gossen, und nun der Krahn des Wasserbehälters A so weit geöffnet, dass jederzeit so viele Tropfen einfliessen, wie unten ablaufen. Die höclist praktische Brauchbarkeit dieser Vorrichtung bedarf keiner weitern Empfehlung; ihre Anwendung gewährt vielfache Vortheile.

\title{
Beschreibung und Gebrauchsanweisung für eine neue Spiritus-Gas-Kochmaschine.
}

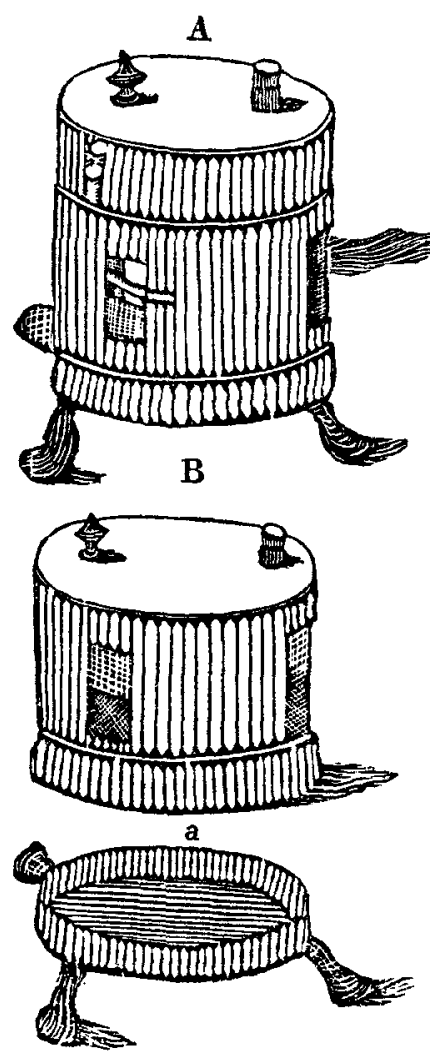

Die Spiritus - Gas - Kochmaschine besteht aus den 4 hier neben unter Fig. a. b. c.d gezeichneten Theilen.

Um sich derselben zum Kochen $\mathrm{zu}$ bedienen, fïlle man Fig. $b$, je nachdem man längere oder kürzere Zeit das Feuer zu unterhalten wünscht, mit mehr oder weniger Spiritus, höchstens jedoch nur bis $z u \frac{2}{3}$ des ganzen Inhalts. Dann stelle man Fig. $b$ in die Mitte auf Fig. a, wobei man $\mathrm{zu}$ beachten hat, dass kein Spiritus auf Fig. a geschüttet werde. Hierauf stellt man Fig. c über Fig. b auf Fig. a und zwar so, dass die über den drei Oeffnungen befindlichen Leisten nach oben kommen. Nun fuille man in Fig. d durch die vermittelst eines 
Pfropfens zu verschliessende

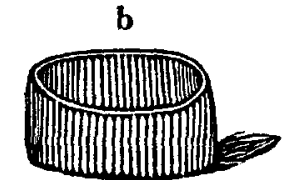

c
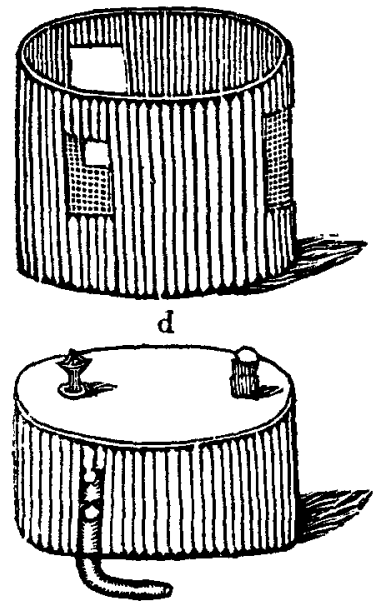

Oeffnung noch ein halbes Mal so viel Spiritus als in Fig. $b$, stecke den Pfropfen dann fest auf und' stelle, nachdem man den Spiritus in Fig. b entzündet hat, Fig. $d$ so auf die Leisten von Fig. c, dass die Oeffnung der unten von Fig. d ausgehenden kleine Röhre ihre Richtung nach der mittJeren den drei in Fig. $c$ befindlichen Oeffinungen erhält. Durch den in Fig. b brennenden Spiritus wird der in Fig. d sehr schnell zum Verdampfen gebracht und diese Spiritusdämpfe nehmen nun ihren Ausgang, wenn der Pfropfen gut schliesst, allein durch die kleine Röhre, an deren Ausgang sie durch den in Fig. $b$ brennenden Spiritus entzündet werden und eine Flamme bilden, welche von dem durch die beiden andern in Fig. $\mathrm{c}$ befindlichen Oeffnungen hervorgebrachten Luftzug lebhaft und mit einem brausenden Geräusch aus der mittleren Oeffnung in einer Länge von 7 bis 10 Zoll hervordringt. Gegen diese, eine sehr bedeutende Hitze hervorbringende Flamme stellt man nun bis zu ihrer Mitte das Gefäss, in welchem man kochen will, wodurch die Flamme sich spaltet und sich um beide Seiten des Gefässes schlingt (siehe oben Fig. A). Es eignen sich zum Gebrauch zwar Gefässe aus allen Stoffen, besonders vortheilhaft aber sind metallne und namentlich blecherne. Ein Quart 
Wasser, in einem blechernen Gefässe der Wirkung der Flamme auf die beschriebene Weise ausgesetzt, wird in wenigen Minuten zum Sieden gebracht. Will man die Flamme löschen, so hebe man Fig. d vermittelst des oben neben dem Pfropfen befindlichen Knopfes von Fig. $\mathrm{c}$ und blase die Flamme in Fig. $b$ aus.

Bei genauer Befolgung dieser Gebrauchsweise wird die Maschine sich gewiss eben so dauerhaft als wirksam bewahren.

Zum bequemeren Transport und zur Raumersparniss kann die Maschine beim Nichtgebrauch verkleinert werden.

Man ziehe die Füsse von Fig. a ah, lege sie in Fig. b, stelle Fig. c. umgekehrt auf Fig. a und in Fig. c wiederum Fig. d (siehe oben Fig. B).

Diese neue Spiritus-Gas-Kochmaschinen sind in zwei verschiedenen Grössen, a $15 \mathrm{Sgr}$. und a $25 \mathrm{Sgr}$. bei uns stets vorräthig, so wie wir auch dazu geeignete Kochtöpfe, à $25 \mathrm{Sgr}$. haben anfertigen lassen, von welchen die Füsse und Griffe abgenommen und nebst der Kochmaschine selbst in das Gefäss gelegt werden können, wodurch der ganze Apparat, auf den möglichst kleinsten Raum beschränkt, sehr leicht transportabel wird und sich auch dadurch zum Gebrauch auf Reisen ganz vorzüglich eignet.

\section{Eisenstein et Comp.}

in Berlin, Jägerstrasse Nr. 52. 